\title{
Bone Health Status among Postmenopausal Women in Malaysia
}

\author{
Mohd Said Nurumal $^{1 *}$, Muhammad Lokman Md. Isa ${ }^{1}$, Nik Noor Kaussar Nik Mohd Hatta ${ }^{1}$, Azlina Daud ${ }^{1}$, \\ Muhammad Ibrahim ${ }^{2}$, Mohd Ariff Sharifudin ${ }^{3}$, Samsul Deraman ${ }^{3}$
}

\begin{abstract}
Objectives: The study has evaluated bone health status among post-menopausal women in a public hospital of Malaysia. Materials and Methods: A total of 116 post-menopausal women, who met the criteria, participated in this study. The purposive sampling method was used to achieve the criteria of participants.

Results: This cross-sectional study revealed that more than half of the respondents $(52.6 \%, \mathrm{n}=61)$ had osteopenia; whereas, $47.4 \%$ $(n=55)$ of the respondents had osteoporosis. There was a significant correlation between the age and menopausal years with the bone health status (i.e. $P=0.004$ and $P=0.028$, respectively) in postmenopausal women.

Conclusions: Menopausal women experienced deterioration of bone mineral density (BMD) with advancing age and menopausal years.

Keywords: Menopausal women, Bone health status, Osteoporosis, Malaysia
\end{abstract}

\section{Introduction}

Bone health status among women declines in the menopausal stages. Women's sedentary lifestyle in older age and decreased level of hormones in a menopausal stage result in increased risk of osteoporosis. Post menopause, the rate of bone loss increases, particularly because of bone turnover uncoupling along with the progression of bone resorption (1). It is observed that throughout the lifespan, the fragility fracture is experienced by 1 in 3 women (aged 50 or above) (2). The percentage reported for episodes of osteoporotic fractures is $61 \%$ whereas the ratio of female to male was 1:6 (3). An increased incidence rate of fracture among elderly individuals suggested that osteoporotic fracture serves as a substantial factor leading to health impairment and death at times (4). This necessitates the implementation of adequate preventive and treatment measures in order to eradicate its prevalence and overcome it.

Across the globe, the increase in the occurrence of osteoporosis as well as the declining status of bone mineral density (BMD) is observed, though its occurrence is three times more in Malaysia. For instance, the cases reported among Malaysian individuals (60 or above age bracket) are expected to increase to 3.3 million in 2050, which were reported to be 1.4 million in 2000 (5). Correspondingly, Malaysia has a higher prevalence rate of osteoporosis (24.1\%) (6).

The prevalence of osteoporosis is projected to be higher in Asia with its expanding aging population. The findings of a recent study revealed that the prevalence of osteoporosis was $10.6 \%$ in men and it was $8.0 \%$ in women. A similar increase in the occurrence of osteoporosis and osteopenia was illustrated in women $(P<0.05)$, which was not found in males $(P>0.05)$ (7).

Women generally have a lower peak bone mass as compared to men (8). Furthermore, the risk of bone loss is higher in females as compared to males, especially in postmenopausal women due to their estrogen deficiency. Estrogen significantly contributes to bone remodeling as it emphasizes the increase of osteoblast activity, favoring bone formation (9). Therefore, the decrease in estrogen during menopause affects the bone-building cells that disrupt the natural process of bone breakdown and repair.

In females, estrogen loss as a result of menopause leads to resorption of the bones up to $90 \%$, whereas $45 \%$ increase is observed in the formation of the bone resulting in the overall bone loss (10). Though it is shown that females have 40 to $50 \%$ risk of developing fractures due to osteoporosis, males have only $13 \%$ to $22 \%$ risk (3). Women are likely to experience breaking down of the bone than building up after 30 years that is enhanced by the intake of poor diet, lifestyle, and family history.

The remodeling pattern of bone also varies based on gender. In females, the bones with fewer minerals are replaced by the one with more, along with the decrease of the trabecular surface. The decline in the trabecular surface increases the stress on the bones amplifying the microdamage to the bones $(11,12)$. However, in males,

Received 11 October 2018, Accepted 19 December 2018, Available online 3 January 2019

${ }^{1}$ Kulliyyah of Nursing, International Islamic University Malaysia (IIUM), Kuantan, Pahang, Malaysia. ${ }^{2}$ Kulliyyah of Allied Health Science, International Islamic University Malaysia (IIUM), Kuantan Campus, Pahang, Malaysia. ${ }^{3}$ Kulliyyah of Medicine, International Islamic University Malaysia (IIUM), Kuantan, Pahang, Malaysia.

*Corresponding Author: Mohd Said Nurumal, Email: mohdsaid@iium.edu.my 
the decrease in the trabecular surface occurs when the bone formation increases (13). Overall, a slight decline in $\mathrm{BMD}$ results is observed in males as compared to postmenopausal females, which indicates that it prevails in later years in men as compared to women (14).

The study by Haentjens et al (15) and Riggs et al (16) state the difference in the bone strength with age. In both of the studies, it is indicated that the cross-sectional area is larger in males in contrast to females. Both of the studies also highlighted that the volumetric bone density is low among the old aged females as compared to males, where increasing age is observed to lead the increase in the size of the bone. The consequences are observed to lower the bone strength among aging females.

In the late premenopausal years, the bone loss accelerates, which continues until the women enter their first postmenopausal years. There is $50 \%$ loss of trabecular bone whereas the cortical bone loss is $30 \%$ throughout the entire female lifetime. In the first ten years, almost half of the percentages are reduced, soon after they enter their menopausal stage (17). This also increases the risk of experiencing fractures among $40 \%$ of the postmenopausal women (18).

The differences in the risk of fracture between the two genders may be elucidated in terms of the bone strength variation. Though, the frequency of fracture is higher among the females, whereas the post-fracture outcomes are more detrimental in males. The paucity of information is observed in terms of BMD changes which prevail among the women in menopause despite the public health importance of post-menopausal osteoporosis. The understanding of the causes of the bone loss acceleration among postmenopausal women is crucial for formulating informed decisions about the appropriate time for proper diagnosis of osteoporosis. Moreover, preventive strategies are needed to be implemented among the population of postmenopausal women. In a similar context, the present study aims to evaluate bone health status among postmenopausal women in a public hospital in Malaysia.

\section{Materials and Methods}

The cross-sectional method was employed in the study. A total of 116 post-menopausal women were recruited using purposive sampling from April 2016 to October 2016. The recruitment of the women was done from the Menopause Clinic, Orthopedic Clinic, and Specialist Clinic Pharmacy of Hospital Tengku Ampuan Afzan (HTAA) located in Kuantan city of Pahang, Malaysia. Women aged 50 years and above were included in the study. Moreover, the criteria for selecting respondents was based on BMD (T-score $<-1$ and SD $>-2.5$ ). The women suffering from any chronic illness were excluded from the study.

The collection of data took place subsequent to obtaining approval from the Institutional Research Ethics Committee (IREC) at the International Islamic University and National Medical Research Registry (NMRR). An interviewer-based questionnaire was employed for gathering participant's demographic characteristics including their age, ethnicity, level of education, socioeconomic status, marital status, and years of having menopause. Data collection was continued with the radiological assessment of BMD. This test was conducted using Hologic Discovery DXA Machine for measuring axial skeleton and appendicular skeleton, similar to a study by Lekamwasam et al (19). The study variables were analyzed using descriptive statistics. Chi-square test was carried out for evaluating the interconnectivity that prevails between the independent variable (i.e. demographic characteristics and bone health status). The determined $P$-value for significant correlation was $P<0$.05. Furthermore, SPSS version 20.0 was utilized for managing and evaluating the collected data.

\section{Results}

Demographic Characteristics and Bone Health Status of Respondents

A total of 116 post-menopausal women, ranging from 49 to 82 years $(\mathrm{M}=61.84, \mathrm{SD}=7.87)$ were examined. It was observed that $61 \%$ of the participants were Chinese. Most of the respondents $(84.5 \%)$ were married or living with a partner. Furthermore, regarding the level of education, it was found that $56.9 \%$ of the participants have attended secondary school and the rest have attended primary schools $(26.7 \%)$. Based on economic status, more than half $(54.3 \%)$ of respondents were in a middle-income category (>RM1000-4000/month). The mean duration of menopause was $12.13(\mathrm{SD} \pm 8.20)$, with a range between 3 and 44 years (Table 1 ).

Overall bone health status of respondents, based on $\mathrm{BMD}$, ranged from -4.8 to $-1.0 \mathrm{SD}(\mathrm{M}=-2.3, \mathrm{SD}=0.84)$ (Figure 1). Moreover, 52.6\% $(\mathrm{n}=61)$ of the participants had osteopenia, whereas $47.4 \%(n=55)$ had osteoporosis.

Association Between Demographic Characteristics and Bone Health Status

Table 2 shows a statistically significant association between demographic characteristics and bone health status. The predominant age group for menopausal women was 49 to 82 years $(M=61.84, S D=7.87)$. A significant correlation was found between the age $(P=0.004)$ and menopausal years $(P=0.028)$ with the bone health status in postmenopausal women. Considering the educational status, significantly low bone health status was found among the women who had a low level of education.

\section{Discussion}

This study evaluated the bone health status among menopausal women in a public hospital of Kuantan, Malaysia. The mean duration of menopause was 12.13, with a range between 3 and 44 years. In a previous study, the mean duration of menopause was 5.8 years (20). The present study revealed that postmenopausal 
Table 1. Demographic Characteristics of Respondents

\begin{tabular}{|c|c|c|c|c|}
\hline Variables & No. & $\%$ & Mean & SD \\
\hline Age & & & 61.84 & 7.87 \\
\hline $50-5$ & 54 & 46.6 & & \\
\hline $60-69$ & 41 & 35.3 & & \\
\hline Above 70 years & 21 & 18.1 & & \\
\hline Menopausal years & & & 12.13 & 8.20 \\
\hline$<10$ & 52 & 44.8 & & \\
\hline $10-19$ & 42 & 36.2 & & \\
\hline $20-29$ & 17 & 14.7 & - & - \\
\hline $30-39$ & 4 & 3.4 & & \\
\hline $40-49$ & 1 & .9 & & \\
\hline \multicolumn{5}{|l|}{ Ethnic } \\
\hline Chinese & 46 & 24.1 & & \\
\hline Indian & 7 & 6 & & \\
\hline Others & 2 & 1.7 & & \\
\hline \multicolumn{5}{|l|}{ Educational level } \\
\hline $\begin{array}{l}\text { Primary } \\
\text { Secondary }\end{array}$ & $\begin{array}{l}31 \\
66\end{array}$ & $\begin{array}{l}26.7 \\
56.9\end{array}$ & - & - \\
\hline College & 14 & 12.1 & & \\
\hline Academic degree & 5 & 4.3 & & \\
\hline \multicolumn{5}{|l|}{ Status } \\
\hline Single & 7 & 6 & & \\
\hline Married & 98 & 84.5 & - & - \\
\hline Divorced & 2 & 1.7 & & \\
\hline Widowed & 9 & 7.8 & & \\
\hline \multicolumn{5}{|l|}{ Income } \\
\hline$<$ RM 1000 & 42 & 36.2 & - & - \\
\hline RM 1000-4000 & 63 & 54.3 & & \\
\hline$>$ RM 5000 & 11 & 9.5 & & \\
\hline
\end{tabular}
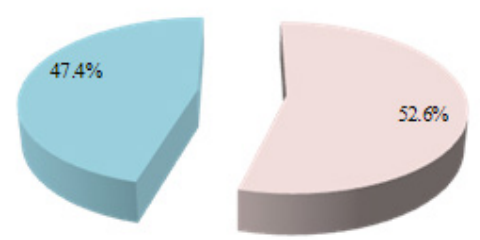

Osteopenia

Osteoporosis

Figure 1. Bone Health Status of Respondents.

women are at increased risk of long-term effects such as osteoporosis. These are in line with the findings of a study by Dalal and Agarwal (21), which also indicated that osteoporosis is the long-term consequence of menopause in women. The results of the present study also highlight that age, longer duration of menopause, and education levels were associated with bone health status, while higher family income, ethnicity, and marital status were not correlated. This study discovered that 116 women among the population of PMW in Kuantan, Pahang, experienced deterioration of bone density. Overall bone health status of respondents ranged from -4.8 to $-1.0 \mathrm{SD}$ $(\mathrm{M}=-2.3, \mathrm{SD}=0.84)$. As per the reporting of World Health Organization (WHO) (22), a BMD T-score of -2.5 or lower is considered osteoporosis in postmenopausal women. However, the low density of the bone or osteopenia is illustrated as the BMD T-score which has SD ranging
Table 2. Association Between Demographic Characteristics and Bone Health Status

\begin{tabular}{|c|c|c|c|}
\hline Variables & Osteopenia & Osteoporosis & $P$ value \\
\hline Age (y) & & & 0.004 \\
\hline $50-59$ & 35 & 19 & \\
\hline $60-69$ & 20 & 21 & \\
\hline$>70$ & 6 & 15 & \\
\hline \multicolumn{4}{|l|}{ Menopausal years } \\
\hline$<10$ & 32 & 20 & 0.028 \\
\hline $10-19$ & 21 & 21 & \\
\hline $20-29$ & 7 & 10 & \\
\hline $30-39$ & 1 & 3 & \\
\hline $40-49$ & 0 & 1 & \\
\hline \multicolumn{4}{|l|}{ Ethnic } \\
\hline Malay & 19 & 17 & \\
\hline Chinese & 37 & 34 & 0.966 \\
\hline Indian & 4 & 3 & \\
\hline Others & 1 & 1 & \\
\hline Educational level & & & 0.016 \\
\hline Primary & 9 & 22 & \\
\hline Secondary & 41 & 25 & \\
\hline College & 7 & 7 & \\
\hline Academic degree & 4 & 1 & \\
\hline Status & & & 0.516 \\
\hline Single & 2 & 5 & \\
\hline Married & 53 & 45 & \\
\hline Divorced & 1 & 1 & \\
\hline Widowed & 5 & 4 & \\
\hline Income & & & 0.270 \\
\hline$<\mathrm{RM} 1000$ & 23 & 19 & \\
\hline RM 1000-4000 & 35 & 28 & \\
\hline >RM 5000 & 3 & 8 & \\
\hline
\end{tabular}

from -0.1 to -2.5 . More than half of the respondents, $52.6 \%(n=61)$, had osteopenia, whereas $47.4 \%(n=55)$ had osteoporosis.

The results of the study are endorsed by several researchers such as Francis et al (23) who elucidated that education interventions improve the bone status among the menopausal women. Similarly, the research by Faubion et al (24) also reported that bone loss is more frequent in premenopausal women. Furthermore, in the study by Paramsothy et al (25), the longer duration of menopause is also observed to have a detrimental impact on the bone health resulting in bone loss. Contrary to the present study, Pedersen et al (26) reported the mediocre effect of income on menopause women while Sharif et al (27) stated that income affects the consumption of dietary food impacting their bone health status. Contrary to the present study, the study by Lin et al (28) suggests that marital status was linked to the bone health of the postmenopausal women.

The deterioration of bone density becomes a serious concern as it increases the risk for the development of osteoporosis. Hasnah et al (29) reported that nearly half $(43 \%)$ of post-menopausal subjects in Cheras, Kuala Lumpur had low bone density; osteoporosis 
and osteopenia. Oh et al (30) in a randomized control trial (RCT) suggested that Korean post-menopausal women had osteopenia and osteoporosis with $75 \%$ of $41 \%$ participants. About 200 million women across the world are projected to be affected by osteoporosis (aged 60: one-tenth, aged 70: one-fifth, aged 80: two-fifths and aged 90: two-thirds) (31). Most of the previous findings corroborated such findings on the prevalence of osteoporosis that contributes to clinical relevance in improving the care. The exponential increase in the incidence of low BMD among post-menopausal raises great concern from the healthcare practitioner to deal with these crucial problems.

Increased prevalence of osteoporosis and deterioration of bone density among post-menopausal women is due to many factors. The common factor associated with the condition of menopause and osteoporosis is estrogen deprivation (32). This study discovers that the length of menopause was associated with deterioration of bone density. In addition, the incidence of osteoporosis is also linked with the age. The episodes of the low bone mass and decline in the microarchitecture of the bone tissue are also closely linked with the increasing age. As the age advances, the loss of the bones, as well as its deteriorating structure, give rise to the fragility of the skeleton as revealed by the low mass of the bone along with its geometrical properties, microarchitecture, and the material properties (33). However, bone health may still be renewed by performing various preventative measures. Changing the lifestyle through proper nutrition and exercise will increase bone density even in advancing age.

A similar cross-sectional study determined BMD and intake of nutritious diet among the post-menopausal women in Kuala Lumpur (29). The results depicted that the health status of these women was low with the active loss of bone mass due to their increased consumption of non-milk diet which increases the occurrence of hip fracture (6). Another study identified the risk factors of osteoporosis among Malaysian women receiving hormone replacement therapy (34). The results showed a decrease in the incidence of osteoporosis among women taking calcium supplements. The study found strong interconnectivity of the women age with the BMD status. Its results clearly depicted that spinal bone loss among post-menopausal women can be prevented through lifestyle intervention that includes physical activity.

The present study showed that there was a significant correlation between the age and menopausal years with the bone health status in postmenopausal women. Moreover, low bone health status was found to be significantly correlated with a low level of education in women. A similar study was conducted by Chin et al (34) which examined the Malaysian women (aged 50 or above) for determining the association of the osteoporosis and the health indices of bone using calcaneal quantitative ultrasound. The results showed that women with old age, increased body fat, as well as a number of pregnancies, were likely to have suboptimal bone health (35).

\section{Conclusions}

This study has demonstrated the deterioration of BMD among menopausal women. There was a correlation between the duration of menopause and advancing age with BMD status. Therefore, it is important to educate and increase cautiousness of the public about maintaining a healthy and active lifestyle to ensure good bone health status, especially in menopausal and older populations. Lifestyle modification through proper nutritional intake and exercise intervention may serve as an effective way to resolve this serious health concern.

However, several limitations were observed in the study. For instance, the study was limited to the female population, therefore, the same results cannot be concluded for males. Furthermore, the result of the present study cannot be generalized to other regions based on the fact that every region varies in terms of size, economy, social aspects and so on. Additionally, it also suggests that future researchers can conduct the same research with a larger sample size and increased length of the study for broadening the horizons.

\section{Conflict of Interests}

Authors declare that they have no conflict of interests.

\section{Financial Support}

This work was supported in part by Fundamental Research Grant (FRGS 105781-135771) from the Ministry of Higher Education (MOHE), Malaysia.

\section{References}

1. Seibel MJ. Biochemical markers of bone turnover: part I: biochemistry and variability. Clin Biochem Rev. 2005;26(4):97-122.

2. International Osteoporosis Foundation (IOF). Facts and Statistics. IOF; 2015.

3. Johnell O, Kanis JA. An estimate of the worldwide prevalence and disability associated with osteoporotic fractures. Osteoporos Int. 2006;17(12):1726-1733. doi:10.1007/s00198-006-0172-4

4. Wheater G, Elshahaly M, Tuck SP, Datta HK, van Laar JM. The clinical utility of bone marker measurements in osteoporosis. J Transl Med. 2013;11:201. doi:10.1186/14795876-11-201

5. Mafauzy M. The problems and challenges of the aging population of malaysia. Malays J Med Sci. 2000;7(1):1-3.

6. Lim PS, Ong FB, Adeeb N, et al. Bone health in urban midlife Malaysian women: risk factors and prevention. Osteoporos Int. 2005;16(12):2069-2079. doi:10.1007/ s00198-005-2003-4

7. Chin KY, Kamaruddin AA, Low NY, Ima-Nirwana S. Effects of age, sex, and ethnicity on bone health status of the elderly in Kuala Lumpur, Malaysia. Clin Interv Aging. 2016;11:767-773. doi:10.2147/cia.s108772 
8. Suman VB PK, Chatterjee PK. Risk factors associated with osteoporosis. Int J Health Sci Res. 2013;3:85-91.

9. Baron R, Hesse E. Update on bone anabolics in osteoporosis treatment: rationale, current status, and perspectives. J Clin Endocrinol Metab. 2012;97(2):311-325. doi:10.1210/ jc.2011-2332

10. Willson T, Nelson SD, Newbold J, Nelson RE, LaFleur J. The clinical epidemiology of male osteoporosis: a review of the recent literature. Clin Epidemiol. 2015;7:65-76. doi:10.2147/clep.s40966

11. Barling PM. Osteoporosis-an increasingly important issue for both young and aging citizens of Malaysia. Int e-J Sci Med Edu. 2013;7(1):1-3.

12. Seeman E, Delmas PD. Bone quality--the material and structural basis of bone strength and fragility. N Engl J Med. 2006;354(21):2250-2261. doi:10.1056/NEJMra053077

13. Khosla S, Riggs BL. Pathophysiology of age-related bone loss and osteoporosis. Endocrinol Metab Clin North Am. 2005;34(4):1015-1030, xi. doi:10.1016/j.ecl.2005.07.009

14. Seeman E. Bone quality: the material and structural basis of bone strength. J Bone Miner Metab. 2008;26(1):1-8. doi:10.1007/s00774-007-0793-5

15. Haentjens P, Magaziner J, Colon-Emeric CS, et al. Metaanalysis: excess mortality after hip fracture among older women and men. Ann Intern Med. 2010;152(6):380-390. doi:10.7326/0003-4819-152-6-201003160-00008

16. Riggs BL, Melton Iii LJ 3rd, Robb RA, et al. Population-based study of age and sex differences in bone volumetric density, size, geometry, and structure at different skeletal sites. J Bone Miner Res. 2004;19(12):1945-1954. doi:10.1359/ jbmr.040916

17. Finkelstein JS, Leder BZ, Burnett SM, et al. Effects of teriparatide, alendronate, or both on bone turnover in osteoporotic men. J Clin Endocrinol Metab. 2006;91(8):2882-2887. doi:10.1210/jc.2006-0190

18. Finkelstein JS, Brockwell SE, Mehta V, et al. Bone mineral density changes during the menopause transition in a multiethnic cohort of women. J Clin Endocrinol Metab. 2008;93(3):861-868. doi:10.1210/jc.2007-1876

19. Lekamwasam S, Rodrigo M, Arachchi WK, Munidasa D. Measurement of spinal bone mineral density on a Hologic Discovery DXA scanner with and without leg elevation. J Clin Densitom. 2007;10(2):170-173. doi:10.1016/j. jocd.2007.01.007

20. Nik Hazlina NH, Sulaiman SA, Hassan II, et al. Randomized controlled trial on the effects of tualang honey and hormonal replacement therapy (HRT) on cardiovascular risk factors, hormonal profiles and bone density among postmenopausal women: a pilot study. J Food Res. 2012;1(2):171-188. doi:10.5539/jfr.v1n2p171

21. Dalal PK, Agarwal M. Postmenopausal syndrome. Indian J Psychiatry. 2015;57(Suppl 2):S222-232. doi:10.4103/00195545.161483

22. World Health Organization (WHO). WHO scientific group on the assessment of osteoporosis at primary health care level. WHO; 2004.
23. Francis KL, Matthews BL, Van Mechelen W, Bennell KL, Osborne RH. Effectiveness of a community-based osteoporosis education and self-management course: a wait list controlled trial. Osteoporos Int. 2009;20(9):1563-1570. doi:10.1007/s00198-009-0834-0

24. Faubion SS, Kuhle CL, Shuster LT, Rocca WA. Long-term health consequences of premature or early menopause and considerations for management. Climacteric. 2015;18(4):483-491. doi:10.3109/13697137.2015.1020484

25. Paramsothy P, Harlow SD, Nan B, et al. Duration of the menopausal transition is longer in women with young age at onset: the multiethnic Study of Women's Health Across the Nation. Menopause. 2017;24(2):142-149. doi:10.1097/ gme.0000000000000736

26. Pedersen JM, Budtz-Jorgensen E, De Roos A, et al. Understanding the relation between socioeconomic position and inflammation in post-menopausal women: education, income and occupational prestige. Eur J Public Health. 2017;27(6):1074-1079. doi:10.1093/eurpub/ckx070

27. Sharif A, Hussain M, Ilyas S, Asif A. Role of dietary pattern in prevention of osteoporosis in post menopausal females. Cell. 2017;331:4838518.

28. Lin J, Chen L, Ni S, et al. Association between sleep quality and bone mineral density in Chinese women vary by age and menopausal status. Sleep Med. 2019;53:75-80. doi:10.1016/j.sleep.2018.09.024

29. Hasnah H, Amin I, Suzana S. Bone health status and lipid profile among post-menopausal malay women in Cheras, Kuala Lumpur. Malays J Nutr. 2012;18(2):161-171.

30. Oh EG, Yoo JY, Lee JE, Hyun SS, Ko IS, Chu SH. Effects of a three-month therapeutic lifestyle modification program to improve bone health in postmenopausal Korean women in a rural community: a randomized controlled trial. Res Nurs Health. 2014;37(4):292-301. doi:10.1002/nur.21608

31. Kanis JA. Assessment of osteoporosis at the primary healthcare level. WHO Collaborating Centre for Metabolic Bone Diseases, University of Sheffield Medical School, 2008.

32. Szulc P. The role of bone turnover markers in monitoring treatment in postmenopausal osteoporosis. Clin Biochem. 2012;45(12):907-919. doi:10.1016/j. clinbiochem.2012.01.022

33. Ensrud KE. Epidemiology of fracture risk with advancing age. J Gerontol A Biol Sci Med Sci. 2013;68(10):1236-1242. doi:10.1093/gerona/glt092

34. Chin KY, Low NY, Dewiputri WI, Ima-Nirwanaa S. Factors Associated with Bone Health in Malaysian Middle-Aged and Elderly Women Assessed via Quantitative Ultrasound. Int J Environ Res Public Health. 2017;14(7). doi:10.3390/ ijerph14070736

35. Amor H, Zeyad A, Sobhy Bakry M, Bosilah AMH, Ben Ali H, Eid Hammadeh M. Protamine Ratio as Predictor of the Fertility Potential of Sperm by Couple Undergoing ICSI. International Journal of Women's Health and Reproduction Sciences. 2018;6(4):400-409. doi:10.15296/ijwhr.2018.67

\footnotetext{
(C) 2019 The Author (s); This is an open-access article distributed under the terms of the Creative Commons Attribution License (http://creativecommons.org/licenses/by/4.0), which permits unrestricted use, distribution, and reproduction in any medium, provided the original work is properly cited.
} 